\title{
Respiratuar Distres Sendromlu Bronkopulmoner Displazi Gelişen Hastalarımızda Klinik ve Demografik \\ Bulgularımız ve Literatürün Gözden Geçirilmesi
}

Our Clinical and Demographical Findings in Our Patients with Respiratory

Distress Syndrome That Developed Bronchopulmonary Dysplasia

Fatma Hilal Yılmaz, Nazlı Dilay Gültekin, Nuriye Tarakçı, Hüseyin Altunhan

Necmettin Erbakan Üniversitesi, Meram Tıp Fakültesi, Neonatoloji Bölümü, Konya

Yazışma Adresi / Correspondence:

Fatma Hilal Yilmaz

Necmettin Erbakan Üniversitesi, Meram Tıp Fakültesi, Neonatoloji Bölümü 42060/Konya/TÜRKiYE

T: +90 $3322236697 \quad$ E-mail: f.h.yilmaz@hotmail.com

Geliş Tarihi / Received : 24.04.2018 Kabul Tarihi / Accepted : 28.05.2018

\footnotetext{
öz

Amaç Bu çalışmanın amacı ünitemizde respiratuar distres sendromu (RDS) tanısı ile takip ve tedavi ettiğimiz preterm bebeklerdeki bronkopulmoner displazi (BPD) görülme oranı, bu bebeklerin klinik ve demografik verileri ve risk faktörleri paylaşılarak gelişen yenidoğan yoğun bakım tekniklerine rağmen hastalığın süreçten nasıl etkilendiğinin belirlemesidir. Sakarya Tıp Dergisi, 2018, 8(2):388-394 )

Gereç ve Meram Tıp Fakültesi Yenidoğan Yoğun Bakım Ünitesi'nde 2017 Ocak ile 2018 Mart ayları arasında, prematürelik nedeniyle yatııırak RDS

Yöntem tanısı ile sürfaktan verilen ve izlemlerinde BPD tanısı alarak, tedavi verdiğimiz 10 olgunun dosyalarından verileri kaydedildi.

Bulgular Ocak 2017- Mart 2018 arasında $10(\% 13,3)$ hasta BPD tanısı aldı. Ortalama doğum haftası 26,5 $\pm 1,64$ (25-29), ortalama doğum kilosu $821,8 \pm 236,9$ gr (1378-490) idi. Olguların $7(\% 70)$ tanesi 28 haftanın altında ve $9(\% 90)$ tanesi 1000 gr'ın altında idi. Olguların $8(\% 80)$

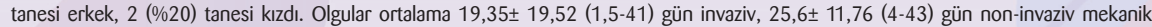
ventilasyon ile solunum desteği aldı. Serbest oksijen ihtiyaçları eve oksijen ile taburcu olan ağır BPD'li 1 hasta hariç ortalama $39,5 \pm 17,19$ (69-14) gün sürdü.

Sonuç Sonuç olarak yenidoğan bakım uygulamalarındaki tüm gelişmelere rağmen BPD ciddi bir sorun olmaya devam etmektedir. Çalışmamızda da prematürite, düşük doğum ağıllğı, invaziv mekanik ventilasyon uygulama süresi, yoğun ve uzun süreli oksijen desteği BPD’nin zemin hazırlayan risk faktörleri olarak öne çıkmaktadır.

Anahtar Bronkopulmoner displazi; respiratuar distres sendromu; prematürite

Kelimeler
}

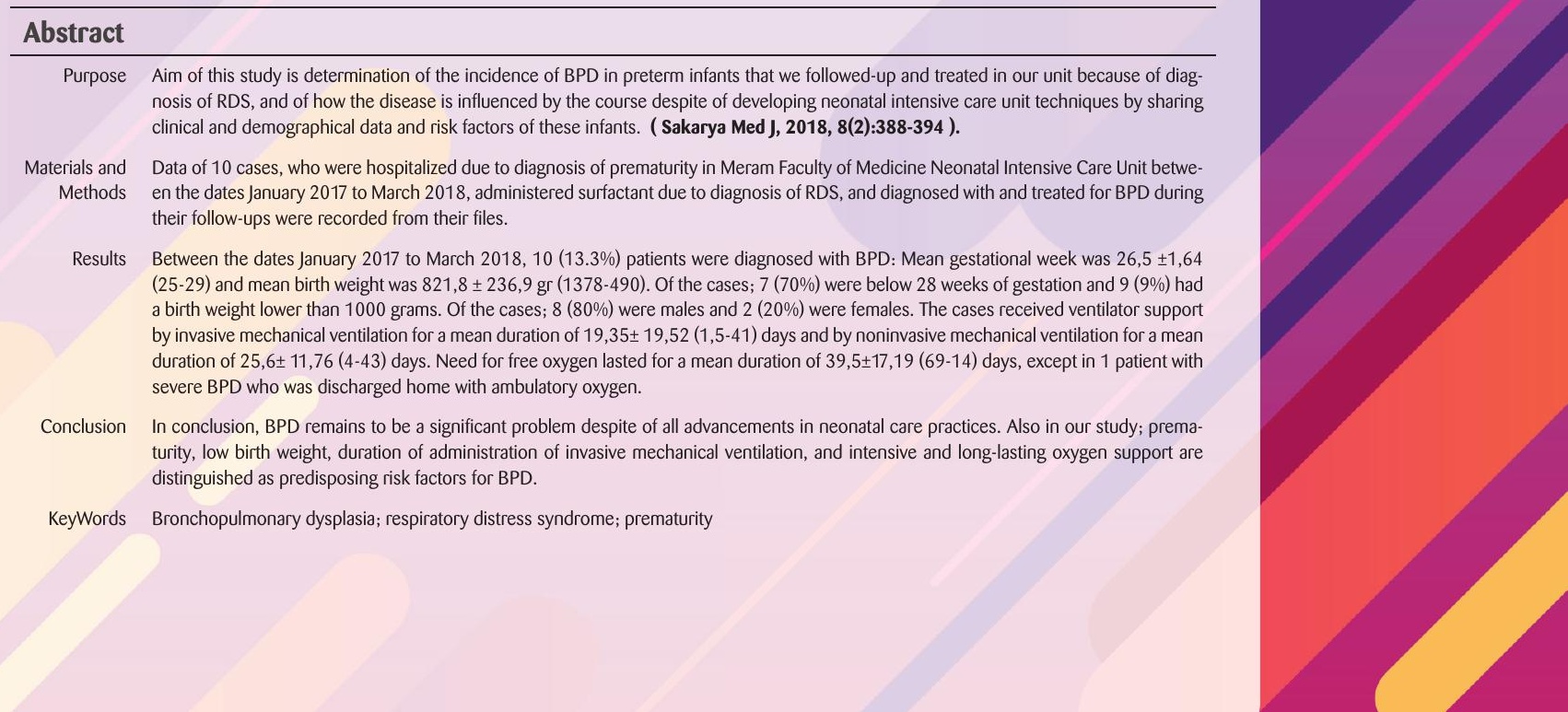


Sakarya TIp Dergisi 2018;8(2):388-394

\section{Giriş}

Bronkopulmoner displazi ilk kez Northway ve arkadaşları tarfından 1967 yılında respiratuar distres tanısı ile tedavi edilip, bir süre invaziv mekanik ventilasyon desteği almış görece büyük prematüre bebeklerin postnatal 28. Gününde hala oksijen ihtiyacı gösteren fibrozisle karakterli kronik akciğer hastalığı olarak tanımlanmıştır. ${ }^{1}$ ilerleyen yıllarda risk altındaki toplumun değişmesi, sürfaktan uygulamaları, antenatal steroid kullanımı ve son 10 yılda daha yoğun olmak üzere daha az invaziv mekanik ventilasyon yönetimlerinin benimsenmesiyle tanımın halihazırdaki hastalığı karşılamadığı düşünülüp hastalığın ciddiyetinin ve gestasyonel yaşın da eklendiği modifiye bir tanımlama daha yapılmıştır (Tablo 1). ${ }^{2}$ Son olarak kabul edilen bu tanımlamanın da hedef hasta grubu olan "Ağır BPD” adayı prematüreleri postkonsepsiyonel 36. haftadan olabildiğince erken yani henüz korunma/tedavi penceresindeyken tanımlayabilmekten uzak olması, uzun dönem solunumsal prognoz, akciğer mekanikleri ve akciğer parankim yapısı hakkında bilgi vermemesi nedeniyle önümüzdeki yıllarda yeni bir tanımlamanın yapılması muhtemel görünmektedir.

\begin{tabular}{|c|c|c|}
\hline & \multicolumn{2}{|c|}{ Gestasyonel Yaş } \\
\hline & $<32$ Hafta & $>32$ Hafta \\
\hline Değerlendirme Zamanı & $\begin{array}{l}\text { Postmenstrüel } 36 . \text { hafta veya } \\
\text { taburculukta* }\end{array}$ & $\begin{array}{c}28 \text { günden fazla oksijen almış } \\
\text { postnatal } 56 \text { gününde ya da tabur- } \\
\text { culukta* }^{*}\end{array}$ \\
\hline \multicolumn{3}{|c|}{28 günden fazla \%21'den fazla oksijen tedavisi almış olmak } \\
\hline Hafif BPD & $\begin{array}{l}\text { 36. Hastada veya taburcu olurken* } \\
\text { oda havası solumakta }\end{array}$ & $\begin{array}{c}\text { 56.günde veya taburcu olurken oda } \\
\text { havası solumakta }\end{array}$ \\
\hline Orta BPD & $\begin{array}{l}\text { 36. Hastada veya taburcu olurken* } \\
<\% 30 \text { oksijen ihtiyacı }\end{array}$ & $\begin{array}{l}\text { 56. günde veya taburcu olurken }{ }^{*}< \\
\% 30 \text { oksijen ihtiyacı }\end{array}$ \\
\hline Ciddi BPD & $\begin{array}{l}\text { 36. Hastada veya taburcu } \\
\text { olurken*>\%30 oksijen veya pozitif } \\
\text { basınç ihtiyacı (NCPAP, IPPV) }\end{array}$ & $\begin{array}{l}\text { 56. günde veya taburcu olurken } \\
\text { *0\%30 oksijen veya pozitif basınç } \\
\text { ihtiyacl (NCPAP, IPPV) }\end{array}$ \\
\hline \multicolumn{3}{|c|}{$\begin{array}{l}\text { Bronchopulmonary dysplasia. Engl J Med 1967; 276: 357-68.Jobe AH, Bancalari E. Bronchopulmonary dyspla- } \\
\text { sia. Am J Respir Crit Care Med 2001; } 163: 1723 . \\
\text { *Hangisi önce gelirse } \\
\text { BPD: Bronkopulmoner displazi } \\
\text { NCPAP: Nazal Sürekli pozitif havayolu basıncı } \\
\text { IPPV: Aralıklı pozitif basınçlı ventilasyon }\end{array}$} \\
\hline
\end{tabular}

Hastalığın literatürdeki insidansı ve prevelansı hakkında muhtelif veriler mevcuttur. United States National Institute of Child Health and Human Development (NICHD) verilerine gore 501-1500 gr arasındaki bebeklerde BPD oranı \%23 olarak bildirilmiştir. ${ }^{3}$ Bronkopulmoner displazi riskinin düşük doğum haftası ve düşük doğum kilosu ile yakından ilişkili olduğu bilinmektedir. Hastalığın etyolojisinde prematürite, koryoamyonit, intra ve ekstrauterin büyüme geriliği, oksidatif stres, mekanik ventilasyon, pre ve postnatal enfeksiyonlar gibi pulmoner gelişimi bozup inflamasyonla sonuçlanan sebepler suçlanmaktadır. Fakat sürfaktan kullanımı, daha az kümülatif dozda oksijen ve non- invaziv mekanik ventilasyon uygulamarının başlangıcı birlikte bunların içerisinde prematürite ve inflamasyon ön plana çıkmaktadır. ${ }^{4}$

Bu çalışmada ünitemizde RDS tanısı ile takip ve tedavi ettiğimiz preterm bebeklerdeki BPD görülme oranı, bu bebeklerin klinik ve demografik verileri ve risk faktörleri paylaşılarak gelişen yenidoğan yoğun bakım tekniklerine rağmen hastalığın süreçten nasıl etkilendiği tartışılmıştır. 


\section{Gereç ve Yöntemler:}

Meram Tıp Fakültesi Yenidoğan Yoğun Bakım Ünitesi'nde 2017 Ocak ile 2018 Mart ayları arasında, prematürelik nedeniyle yatıılarak RDS tanısı ile sürfaktan verilen ve izlemlerinde BPD tanıSı alarak, tedavi verdiğimiz 10 olguyu retrospektif olarak gözden geçirdik. Çalışma olgu serisi olarak tasarlandı. Olgular, gestasyon yaşları, cinsiyetleri, annede enfeksiyon öyküsü, antenatal steroid uygulaması, invaziv ve non-invaziv mekanik ventilatörde kalma süresi, oksijen alma süresi, patent duktus arteriozus (PDA) varlığı ve tedavisi, sepsis, prematüre retinopatisi (ROP), intraventriküler kanama (IVK) gelişimleri, taburculuk süreleri açııından değerlendirildi. Hastaların klinik özellikleri şu şekilde tanımlandı: RDS; klinik bulgu ve akciğer grafisine göre tanı aldı. Surfaktan anormal kan gazı sonuçları ve akciğer grafisinde RDS tanısı almış hastalara verildi. Small gestational age (SGA); 10p altında doğum ağılığı olan bebekler, erken başlangıçı sepsis (postnatak 7 gün) ve geç başlangıçı sepsis (postnatal 7 ve daha geç dönemde) kan kültüründe mikroorganizmanın ürediği durumlar, iVK; ilk on günde yapılan kranial ultrasonografi ile Papile sınıflamasına göre yapıldı ve $\geq$ grade 3 kaydedildi. Nekrotizan enterokolit (NEK); Bell's kriterleri kullanılarak grade $\geq 3$ hastalar kaydedildi. ROP uluslararası ROP sınıflamasına göre tanı aldı. Hemodinamik açıdan anlamlı PDA; yaşamın 3 - 4. günlerinde yapılan ekokardiyografide, internal duktal çapın $1.5 \mathrm{~mm}$ üstünde, sol pulmoner arter dopler akımı 0,2m/sn'nin üzerinde ve sol atriumun aort köküne oranı (LA/Ao) $1.5 \mathrm{~mm}$ olması durumunda düşünüldü ve tedavi verildi. BPD tanısı postkonsepsiyonel 36. haftada veya yaşamın 28. gününde oksijen bağımlığının sürmesi ve radyolojik bulgulara dayanılarak konuldu.

\section{Bulgular:}

Ocak 2017- Mart 2018 arasında yenidoğan yoğun bakım ünitesine kabul edilmiş olan toplam 1189 hastadan 75 hasta respiratuar distres tanısı ile sürfaktan verilerek takip edildi. Bu hastalardan 10 $(\% 13,3)$ tanesine BPD tanısı konuldu. Olguların ortalama doğum haftası 26,5 $\pm 1,64$ (25-29), ortalama doğum kilosu $821,8 \pm 236,9$ gr (1378-490) idi. Olguların 7 (\%70) tanesi 28 haftanın altında ve $9(\% 90)$ tanesi 1000 gr'ın altında idi. Olguların 8 (\%80) tanesi erkek, 2 (\%20) tanesi kızdı. íki olgunun annesinde koryoamyonit olduğu tespit edildi. Olguların $4(\% 40)$ tanesine antenatal steroid uygulanmıştı ve tamamı sezaryen ile dünyaya gelmişti. Olgular ortalama 19,35 19,52 (1,5-41) gün invaziv, 25,6 11,76 (4-43) gün non-invaziv mekanik ventilasyon ile solunum desteği aldı. Serbest oksijen ihtiyaçları eve oksijen ile taburcu olan ağır BPD'li 1 hasta hariç ortalama 39,5 517,19 (69-14) gün sürdü. Üç (\%30) hastada geç neoanatal sepsis görüldü. Bir tanesi Klebsiella pneumonia, 2 tanesi koagülaz negatif stafilokok idi. Beş (\%50) hastaya hemodinamik anlamlı PDA nedeniyle tedavi verildi 4 tanesi medikal tedavi (ibuprofen $10 \mathrm{mg} / \mathrm{kg}, 5 \mathrm{mg} / \mathrm{kg}, 5 \mathrm{mg} / \mathrm{kg}$ ) ile kapanırken, 1 tanesi cerrahi olarak kapatıldı. Olguların 3 tanesinde kültür ile kanıtlanmış sepsis görüldü. Yedi (\%70) olguda ROP gelişti, 4 tanesi tedavi gerektirdi diğerleri kendiliğinden geriledi. Olguların hiç birinde NEK görülmez iken, 9 (\%90)'da IVK vardı; 5 tanesi evre 3 ve üzeri, 4 tanesi evre 2 ve altında idi. Taburcu olma süreleri ortalama 89,1 \pm 21,04 (58-123) gün olarak belirlendi. Yalnızca 1 hastaya pulmoner hipertansiyon, 3 hastaya ise geç sistemik deksametazon tedavisi verildi. Deksametazon tedavisi maksimum 5 , minumum 3 gün süre ile uygulandı. Herhangi bir yan etki izlenmedi. Hastaların demografik ve klinik özellikleri tablo 2'de özetlendi.

\section{İstatistik:}

İstatistiksel analiz, IBM SPSS istatistik sürümü 21.0 ile yapıldı. Sonuçlar ortalama \pm standart sapma (SD) (minimum-maksimum) olarak ifade edildi.
Sakarya Tıp Dergisi $2018 ; 8(2): 388-394$

YILMAZ ve Ark. Respiratuar Distres Sendromlularda Bronkopulmoner Displazi Oranımı 
zın yalnızca 2 tanesinde (Annede mikrobiyolojik olarak gösterilmiş) koryoamyonit varlığı pozitif olarak kabul edildi. Ilk 1 ay içinde meydana gelen nazokomiyal enfeksiyonların bebeğin ventilatörde kalma süresini uzatıp BPD gelişimine katkıda bulunduğu düşünülmektedir. Özellikle koagülaz negatif stafilokokların BPD riskini artırdığı ortaya konulmuştur. ${ }^{6}$ Üç olgumuzda geç neonatal sepsis gelişmiş ve literatürle uyumlu olarak bunların \%67'sinde KNS olduğu görülmüşsür.

Mekanik ventilasyon preterm bebeklerde aşırı havalanma, alveolar kollaps ve inflamatuar mediatörlerin salınımına sebep olarak inflamasyonun tetiklenmesiyle BPD gelişimine zemin hazırlamaktadır. ${ }^{12}$ Entübe takip edilmeyi gerektiren olgularda bu süreci en az hasar ile atlatmak adına tidal hacim hedefli ventilasyon modlarının tercih edilmesi en kısa sürede hastanın ekstübe edilerek non-invaziv ventilasyon ile takibe alınması önerilmektedir. ${ }^{13}$ Hastalarımızın ortalamada uzun süreli invaziv ventilasyon ihtiyacı gösterdiği görülmektedir. Şiddetli RDS ve sekonder enfeksiyonların eklenmesi invaziv mekanik ventilasyon süresinin uzamasına sebep olmakta bu da beraberinde BPD görülme sıklığını artırmaktadır.

Antioksidan mekanizmaları yetersiz olan pretermlerde -miktarı ve kümülatif dozu tam olarak belirlenememekle birlikte- uzun süreli oksijen maruziyetini sonucu oksijen radikallerinin akciğer parankiminde bozukluğa, sürfaktan yapısında inaktivasyona yol açarak BPD’ye sebep olduğu ileri sürülmektedir. Jobe ve arkadaşları çalışmalarında yaşamın ilk 2 haftasında maruz kalınan kümülatif oksijen miktarı ile BDP gelişme riskinin doğru orantılı artığını ileri sürmüşslerdir. ${ }^{14}$ Bu çalışmada hastaların 39,5ะ17,19 gün ile uzun süre oksijene ihtiyaç gösterdiği görülmektedir.

Üzerinde çok tartışılan diğer bir konu olan hedef satürasyon değerleri içinse 2017 yllında 5000 preterm bebeğin dahil edildiği bir metaanalizde düşük hedef satürasyon (\%85-89) grubu ile yüksek hedef satürasyon (\%91-95) grubu arasında BPD açısından fark bulunmamıştı. ${ }^{15}$ Bu nedenle son rehberlere göre prematüre bebeklerin, ek oksijen gereksinimi devam ettiği sürece, PM 36. haftaya kadar oksijen satürasyonları aralığının \%90-95 tutulması önerilmektedir. Bizim olgularımızda \%91-95 satürasyon aralı̆ı̆nda takip edildiler.

Patent duktus arteriozus soldan sağa şant nedeniyle akciğerde sıvı yüklenmesine sebep olur. Fazla sIVı nötrofil marjinasyonu ve aktivasyonuna yol açarak akciğer dokusunda hasar meydana getirir. Bronkopulmoner displazinin erken dönemde tanınması veya öngörülmesi ile ilgili yapılan çalışmalarda PDA'nın, en önemli belirteçlerden biri olarak ortaya çıktığı görülmektedir. ${ }^{16}$ Bu çalışmada hastaların yarısında hemodinamik anlamlı PDA görülürken diğer yarısında görülmedi. Hemodinamik anlamlı PDA görülen hastaların 4’ü (\%80) medikal, 1’i (\%20) cerrahi olarak tedavi edildi. Hemodinamik anlamlı PDA yönetim şeklinin BPD ile ilişkisini konu edinen bir metaanalizde tedavi şeklinin BPD gelişiminde tek başına ve doğrudan etkili olmadığı ortaya konulmuştur. ${ }^{17}$

Hastaların taburcu olma sürelerinin ortalama 89,1 \pm 21,04 (58-123) gün ile uzun olduğu görülmektedir. Bu da beraberinde ciddi bir ekonomik maliyeti getirmektedir. Üstelik bu hastaların taburculuk sonrasında da ilk 2 yaşta hastane yatışlarda (\%40-60) ve mortalitede artış olduğunu bildiren çalışmalar vardır. ${ }^{18,19}$

Sonuç olarak yenidoğan bakım uygulamalarındaki tüm gelişmelere rağmen BPD ciddi bir sorun olmaya devam etmektedir. Çalışmamızda da prematürite, düşük doğum ağırlığı, invaziv mekanik ventilasyon uygulama süresi, yoğun ve uzun süreli oksijen desteği BPD'nin zemin hazırlayan risk
Sakarya Tıp Dergisi

2018;8(2):388-394

YILMAZ ve Ark.

Respiratuar Distres Sendromlularda

Bronkopulmoner Displazi Oranımız 
faktörleri olarak literatüre parelel şekilde öne çıkmaktadır. Hastalığa halen postmenstrüel 36. Haftada konulmaktadır. Tanı aşamasından önce BPD’nin görülme riskini ve hastalık şiddetini azaltma potansiyel taşıyan prematüriteliğin engellenmeye çalışııası, pretermlerin uygun şartlarada doğum odasında stabillenmeleri ve non-invaziv ventilasyona öncelik verilmesi, enfeksiyonların yönetimi, yoğun ve uzun süresi oksijen uygulamalarından kaçınılması gerekmektedir. 
1. Northway WH Jr, Rosan RC, Porter DY. Pulmonary disease following respirator therapy of hyaline-membrane disease. N Engl J Med. 1967 Feb 16;276(7):357-68.

2. Bronchopulmonary dysplasia. Engl J Med 1967; 276: 357-68.Jobe AH, Bancalari E. Bronchopulmonary dysplasia. Am J Respir Crit Care Med 2001; 163:1723.

3. Fanaroff AA, Stoll BJ, Wright LL et al. Trends in neonatal morbidity and mortality for very low birth weight infants. Am J Obstet Gynecol 2007;196:1-8

4. Jensen EA, Schmidt B. Epidemiology of bronchopulmonary dysplasia. Birth Defects Res A Clin Mol Teratol 2014; 100:145.

5. Birenbaum HJ, Dentry A, Cirelli J, Helou S, Pane MA, Star K, Melick CF, Updegraff L, Arnold C, Tamayo A, Torres V, Gungon N, Liverman S Reduction in the incidence of chronic lung disease in very low birth weight infants: results of a quality improvement process in a tertiary level neonatal intensive care unit. Pediatrics 2009;123(1):44-50

6. Özkan H, Köksal N, C etinkaya M et al. Risk factors for broncho-pulmonary dysplasia. Güncel Pediatri 2008;6:66-71

7. Zeitlin J, Draper ES, Kollee I et al. Differences in rates and short term outcome of the births before 32 weeks of gestation in Europe in 2003: results from the MOSAIC cohort. Pediatrics 2008;121:936-44

8. Payne NR, LaCorte M, Karna P, Chen S, Finkelstein M, Goldsmith JP, Carpenter JH; Breathsavers Group, Vermont Oxford Network Neonatal Intensive Care Quality Improvement Collaborative. Reduction of bronchopulmonary dysplasia after participation in the Breathsavers Group of the Vermont Oxford Network Neonatal Intensive Care Quality Improvement Collaborative. Pediatrics. 2006;118:73-7

9. Bhandari V, Bizzarro MJ, Shetty A, Zhong X, Page GP, Zhang H, Ment LR, Gruen JR Familial and genetic susceptibility to major neonatal morbidities in preterm twins. Pediatrics 2006;117(6):1901-06
10. Chorioamnionitis alters the response to surfactant in preterm infants Been JV, Rours IG, Kornelisse RF, Jonkers F, de Krijger RR, Zimmermann LJ Pediatr. 2010;156(1):10.

11. Hartling L, Liang Y, Lacaze-Masmonteil T. Chorioamnionitis as a risk facto for bronchopulmonary dysplasia: a systematic review and meta-analysis. Arch Dis Child Fetal Neonatal Ed. 2012;97(1):F8-F17.

12. Coalson Jj. Pathology of new bronchopulmonary dysplasia. Semin Neonatol. 2003;8(1):73-81.

13. Klingenberg C, Wheeler K, McCallion N, Morley C), Davis PG. Volume-targeted versus pressure-limited ventilation in the neonate. Cochrane Database of Systematic Reviews 2017

14. Jobe AH, Bancalari E. Bronchopulmonary Dysplasia. AmJ Respir Crit Care Med 2001;163:1723-9

15. Askie LM, Darlow BA, Davis PG et al. Effects of targeting lower versus higher arterial oxygen saturations on death or disability in preterm infants. Cochrane Database of Systematic Reviews 2017, CD011190.

16. Gursoy T, Hayran M, Derin H, Ovali F. A clinical scoring system to predict the development of bronchopulmonary dysplasia. Am J Perinatol. 2015;32(7):659-66

17. Slaughter J, Reagan PB, Newman TB, Klebanof MA. Comparative Effectiveness of Nonsteroidal Anti-inflammatory Drug Treatment vs No Treatment for Patent Ductus Arteriosus in Preterm Infants. JAMA Pediatr 2017; $171: 164354$

18. Cunningham CK, McMillan JA, Gross SJ. Rehospitalization for respiratory illness in infants of less than 32 weeks' gestation. Pediatrics. 1991;88(3):527-32.

19. Yurttutan S, Korkmaz A, Yiğit Ş, Yurdakök M, Tekinalp G. Bronkopulmoner displazili bebeklerin kısa ve uzun süreli izlemi: on ylllık deneyim. Çocuk Sağlığı ve Hastalıkları Dergisi 2011; 54: 1-15 $\pi$
$>$
$<$
$z$
$>$
$\pi$
$D$
$D$
$D$

Sakarya Tıp Dergisi

2018;8(2):388-394

YILMAZ ve Ark.

Respiratuar Distres Sendromlularda

Bronkopulmoner Displazi Oranımız 